\title{
An Investigation of the Cultural Characteristics Associated with Female Message Sources in South African Print Advertisements in Drum Magazine
}

\author{
Mlenga G. Jere \\ Graduate School of Business, University of Cape Town \\ Private Bag X3, Rondebosch 7701, South Africa \\ Email:mlenga.jere@gsb.uct.ac.za \\ Steven Michael Burgess \\ Nelson Mandela Metropolitan University Business School \\ 14 Bird Street, Port Elizabeth, South Africa 6001 \\ Email: steve.burgess@nmmu.ac.za
}

Doi:10.5901/mjss.2014.v5n23p36

\section{Abstract}

The paper investigates the cultural characteristics associated with female massage sources in print advertisements using Schwartz's Portrait Values Questionnaire (PVQ). The paper is based on a quantitative analysis of a sample of 244 print advertisements drawn from the South African general interest magazine Drum. The content analysis was performed by independent coders and resulted in high levels of intercoder reliability. The results show that the top two values emphasised in the advertisements are achievement and power in the self-enhancement value domain. These results are not consistent with previous studies and appear to be at variance with the ubuntu-inspired values one would expect to find amongst the target readers of the magazine. The paper concludes that use of messages that conflict with consumers' value systems could be a call for more research to understand the target audience better. The limitations of the study and opportunities for further research are identified.

Keywords: cultural values, print advertisements, message source, Portrait Values Questionnaire, content analysis

\section{Introduction}

Advertising research shows that the image of a message source (i.e., the central person in an advertisement) is an important influencer of attitude formation and change. Explanations from theories of attitude formation and change suggest that consumer assessments of message source characteristics help determine the process by which consumers respond to an advertising message and the depth and duration of persuasive effects (Kelman 1961). Message source effects are therefore an important topic for research in advertising and consumer research (e.g., Clark, Evans, \& Wegener 2011). In particular, the portrayal of women is an important subtopic in the source effects literature (Coltrane \& Messineo 2000; Courtney \& Lockeretz 1971; Davis 1990; O'Kelly \& Bloomquist 1976). Research in this subtopic is motivated by at least two factors. Firstly, media portrayals of women can provide insights into the social and cultural condition regarding the treatment of women and provide an indication of the roles, status, and relative power of women (Hovland, MacMahan, Lee, Hwang \& Kim, 2005). Secondly, advertisements influence consumers' values and attitudes regarding the role and status of women in society (McCombs, Llamas, Lopez-Escobar \& Rey 1997).

In this paper, we examine a sample of advertisements drawn from Drum magazine, a leading South African general interest family magazine targeted primarily at black readers. In the examination of these advertisements, we use subjective assessments of cultural content in the advertisements by independent coders selected from the magazine's target market. The cultural assessments were based on Schwartz's Portrait Values Questionnaire (PVQ) (Schwartz et al. 2001). The objective of this paper is to identify patterns in the portrayal of women in print advertisements based on the cultural characteristics associated with the women's images.

\section{Literature Review}

Society and social behaviour can be explained in part by examining everyday forms of social interaction including those 
depicted in advertisements (Goffman 1979; Schaeffer \& Lamm 1992). Advertisements tend to portray traditional gender roles regarding women and men. For example, men and masculinity are profiled as all-important, dominating, and workplace oriented while women and femininity are profiled as nurturing, compliant, and home and housekeeping oriented (Connell 1987). According to identity theory, individuals construct shared meanings through interactions with others, including the interactions seen in advertisements (Charon 1995). Identity theory posits that identities such as one's gender identity are constructed from, reinforced, and validated by different types of information that an individual encounter in life (Milkie 1994). Advertisements are among the many factors that influence people encounter and impact on people's expectations, attitudes, opinions and behaviours (Cortese 1999). Hence, the portrayal of women in advertisements is an important topic for research.

Researchers attribute the learning that people acquire from advertisements to two theories of socialisation namely social learning theory (Moschis \& Churchill 1978) and cultivation theory (Gerbner, Gross, Morgan \& Signorielli 1986; Morgan \& Signorielli 1990). According to social learning theory (Bandura 1977), people learn from observing others. Advertisements also present opportunities for social learning, as consumers observe the values, attitudes, beliefs and behaviours of people portrayed in the visual images and text of advertisements. Cultivation theory explains that beliefs and attitudes acquired through long-term exposure and interaction with socialisation agents such as advertising influence perceptions of social reality (Gerbner, et al. 1986; McQuail 2000; Morgan \& Signorielli 1990). Thus, distortions and stereotypes in advertisements may influence consumers' perceptions of reality (McQuail 2000). Cultivation theory also suggests that how people are portrayed may influence how they come to perceive themselves and relate to others in society (Shrum 1996). Therefore, the cultural characteristics associated with message sources in print advertisements potentially contain important information from which people learn.

\subsection{Cultural characteristics of in advertisements}

Cultural values are known to correlate with consumer behaviour (Henry 1976). In marketing, culture may be operationalised by using values (Usunier \& Lee 2009). An important theory regarding values is the value contents and structure theory (Schwartz 1994; Schwartz, et al. 2001) (Its theoretical contents are summarised in Table 1). Values are enduring, desirable transsituational goals that vary in importance and serve as guiding principles in the life of a person or other social entity (Rokeach 1973; Schwartz 1994). "Implicit in this definition of values as goals is that (1) they serve the interests of some social entity, (2) they can motivate action - giving it direction and emotional intensity, (3) they function as standards for judging and justifying action, and (4) they are acquired both through socialization to dominant group values and through the unique learning experiences of individuals" (Schwartz 1994: 21).

Table 1: Value Constructs, Definitions, and Examples

\begin{tabular}{|c|c|c|}
\hline Value construc & Definition & Examples of PVQ items \\
\hline Power & $\begin{array}{l}\text { Social status and prestige, control or dominance over } \\
\text { people and resources. }\end{array}$ & $\begin{array}{l}\text { He likes to be in charge and tell others what to do. He wants } \\
\text { people to do what he says. }\end{array}$ \\
\hline Achievement & $\begin{array}{l}\text { Personal success through demonstrating competence } \\
\text { according to social standards. }\end{array}$ & $\begin{array}{l}\text { Being very successful is important to him. He likes to stand } \\
\text { out and to impress other people. }\end{array}$ \\
\hline Hedonism & Pleasure and sensuous gratification for oneself. & $\begin{array}{l}\text { He really wants to enjoy life. Having a good time is very } \\
\text { important to him. }\end{array}$ \\
\hline Stimulation & Excitement, novelty, and challenge in life. & $\begin{array}{l}\text { He looks for adventures and likes to take risks. He wants to } \\
\text { have an exciting life. }\end{array}$ \\
\hline Self-direction & $\begin{array}{l}\text { Independent thought and action-choosing, creating, } \\
\text { exploring. }\end{array}$ & $\begin{array}{l}\text { He thinks it's important to be interested in things. He is } \\
\text { curious and tries to understand everything. }\end{array}$ \\
\hline Universalism & $\begin{array}{l}\text { Understanding, appreciation, tolerance and protection } \\
\text { for the welfare of all people and for nature. }\end{array}$ & $\begin{array}{l}\text { He thinks it is important that every person in the world should } \\
\text { be treated equally. He wants justice for everybody, even for } \\
\text { people he doesn't know. }\end{array}$ \\
\hline Benevolence & $\begin{array}{l}\text { Preservation and enhancement of the welfare of people } \\
\text { with whom one is in frequent personal contact. }\end{array}$ & $\begin{array}{l}\text { He always wants to help the people who are close to him. It's } \\
\text { very important to him to care for the people he knows and } \\
\text { likes. }\end{array}$ \\
\hline Tradition & $\begin{array}{l}\text { Respect, commitment and acceptance of the customs and } \\
\text { ideas that traditional culture or religion provide the self. }\end{array}$ & $\begin{array}{l}\text { He thinks it is important to do things the way he learned from } \\
\text { his family. He wants to follow their customs and traditions. }\end{array}$ \\
\hline Conformity & $\begin{array}{l}\text { Restraint of actions, inclinations, and impulses likely to } \\
\text { upset or harm others and violate social expectation or } \\
\text { norms. }\end{array}$ & $\begin{array}{l}\text { He believes that people should do what they are told. He } \\
\text { thinks people should follow rules at all times, even when no } \\
\text { one is watching. }\end{array}$ \\
\hline Security & $\begin{array}{l}\text { Safety, harmony and stability of society, of relationships, } \\
\text { and of self. }\end{array}$ & $\begin{array}{l}\text { The safety of his country is very important to him. He wants } \\
\text { his country to be safe from its enemies. }\end{array}$ \\
\hline
\end{tabular}

Source: Schwartz et al. (2001: 521) 
Schwartz's PVQ explains the contents and structure of human values, in which compatibilities and conflicts can be represented by proximity or opposition in a circular structure of relations. The ten motivational types of values, which are summarised in Table 1, may be summarised by two orthogonal dimensions of values namely self-enhancement vs. selftranscendence, and openness to change vs. conservation. According to Schwartz (1992: 43), the self-enhancement vs. self-transcendence orthogonal dimension of values refers to "values in terms of the extent to which they motivate people to enhance their own personal interests (even at the expense of others) versus to transcend selfish concerns and promote the welfare of others, close and distant, and of nature". The values types that make up the self-enhancement value domain and the self-transcendence value domain are power and achievement, and benevolence and universalism respectively. On the self-enhancement vs. self-transcendence orthogonal dimensions the self-enhancement values are in conflict with the self-transcendence values. The resultant self-transcendence on this dimension is determined by assessing the extent to which a person prioritises self-transcendence values over self-enhancement values (i.e., resultant self-transcendence $=$ self-transcendence - self-enhancement).

The openness to change vs. conservation orthogonal dimension refers to "values in terms of the extent to which they motivate people to preserve the status quo and the certainty it provides in relationships with close others, institutions, and traditions versus following their own emotional and intellectual interests in unpredictable and uncertain directions' (Schwartz 1992: 43). The values types that make up the openness to change value domain and the conservation value domain are self-direction, stimulation and hedonism, and tradition, conformity, and security, respectively. On this orthogonal dimension, the openness to change values are in conflict with the conservation values. The resultant conservation on this dimension is determined by assessing the extent to which a person prioritises conservation values over openness to change values (i.e., resultant conservation = conservation - openness to change).

Values are the most widely used construct in the study of culture (Hofstede 1984; Rokeach 1973; Schwartz 1994) that is used to describe and explain cultural differences. They are influenced by the culture in which the individuals or groups reside (Hofstede 1984; Rokeach 1973; Schwartz 1994) and tend to be relatively stable and consistent over time (Rokeach 1973; Schwartz 1994).

\subsection{South African values}

In studies involving large and nationally representative samples, Burgess (2002) found that the PVQ scale was reliable and valid, and that the value priorities of South Africans and the four Apartheid legacy race groups (i.e., White, Black, Coloured and Asian) were remarkably stable for the years 1997-2001. Burgess (2002) also found the relative ordering of value priorities to be very similar across groups (Table 2). Irrespective of race, the three most important values were security, benevolence, and universalism. The three least important values on the other hand were stimulation, hedonism, and achievement. In a study of South African social axioms and values in a large, representative metropolitan sample, Burgess (2011) found that the value priorities of South African population remained remarkably stable in all groups. It is not evident that these value priorities and social axioms in the general population groups of South Africa as discussed above would be found in the images of women in advertisements in a general interest magazine such as Drum. It is this question that this study addresses. The importance of understanding the cultural characteristics associated with women in advertisements as central characters is premised on the assumption that how women are portrayed influences the persuasiveness of advertisements and how the advertisements are processed. 
Table 2: Value Priorities amongst South African Population Groups: 1997-1999, 2001

\begin{tabular}{|c|c|c|c|c|c|c|c|c|c|c|c|c|c|c|c|c|}
\hline \multirow{2}{*}{ Mean ratings } & \multicolumn{4}{|c|}{1997} & \multicolumn{4}{|c|}{1998} & \multicolumn{4}{|c|}{1999} & \multicolumn{4}{|c|}{2001} \\
\hline & A & $\mathrm{B}$ & $\mathrm{C}$ & W & A & $B$ & $\mathrm{C}$ & W & A & $\mathrm{B}$ & $\mathrm{C}$ & W & A & $\mathrm{B}$ & $C$ & W \\
\hline \multicolumn{17}{|l|}{ Value types } \\
\hline Benevolence & 5.24 & 4.95 & 5.15 & 5.40 & 5.35 & 4.75 & 5.28 & 5.44 & 4.97 & 4.84 & 5.20 & 5.45 & 4.51 & 4.91 & 5.04 & 5.21 \\
\hline Universalism & .06 & 4.93 & 5.00 & 5.01 & 5.13 & 4.76 & 5.14 & 5.01 & 5.11 & 4.82 & 5.04 & 4.99 & 5.07 & 4.97 & 5.41 & 5.44 \\
\hline Conformity & .26 & 4.80 & 4.43 & 4.55 & 4.93 & 4.96 & 5.05 & 4.88 & 4.87 & 5.00 & 5.00 & 4.88 & 4.35 & 4.53 & 4.47 & 4.21 \\
\hline Tradition & .57 & 4.57 & 4.42 & 4.47 & 4.68 & 4.47 & 4.50 & 4.34 & 5.47 & 4.59 & 4.51 & 4.38 & 4.53 & 4.53 & 4.87 & 4.30 \\
\hline Security & .32 & 5.17 & 5.16 & 5.44 & 5.42 & 5.04 & 5.36 & 5.36 & 5.24 & 5.05 & 5.22 & 5.28 & 5.00 & 5.16 & 5.34 & 5.34 \\
\hline Power & 4.34 & 4.57 & 3.98 & 4.07 & 2.84 & 3.71 & 2.85 & 3.08 & 2.87 & 3.90 & 2.73 & 3.12 & 3.49 & 3.59 & 2.34 & 3.41 \\
\hline Achievement & 4.24 & 4.60 & 3.83 & 4.19 & 4.06 & 4.50 & 4.10 & 4.30 & 4.09 & 4.55 & 4.07 & 4.16 & 4.31 & 4.78 & 4.12 & 4.10 \\
\hline Hedonism & 4.14 & 4.47 & 3.85 & 4.02 & 3.95 & 4.34 & 3.96 & 4.12 & 3.86 & 4.45 & 4.08 & 4.19 & 4.53 & 4.65 & 3.71 & 4.39 \\
\hline Stimulat & & 3.89 & 3.55 & 3.90 & 3.62 & 3.92 & 3.65 & 3.94 & 3.71 & 4.06 & 3.77 & 3.97 & 4.21 & 4.58 & 3.75 & 4.14 \\
\hline Self-direction & 4.68 & 4.72 & 4.46 & 4.82 & 4.41 & 4.49 & 4.46 & 4.78 & 4.44 & 4.61 & 4.60 & 4.88 & 4.67 & 4.96 & 4.91 & 4.91 \\
\hline \multicolumn{17}{|l|}{ Value domains } \\
\hline Self-transcendence & 0.21 & 5.02 & 5.14 & 5.28 & 5.24 & 4.76 & 5.21 & 5.22 & 5.21 & 4.83 & 5.12 & 5.22 & 4.79 & 4.94 & 5.22 & 5.21 \\
\hline Conservation & 4.41 & 4.69 & 4.43 & 4.51 & 5.01 & 4.82 & 4.97 & 4.86 & 4.90 & 4.88 & 4.91 & 4.85 & 4.63 & 4.74 & 5.89 & 4.61 \\
\hline Self-enhancement & 4.17 & 4.59 & 3.90 & 4.13 & 3.45 & 4.11 & 3.47 & 3.69 & 4.05 & 4.22 & 3.40 & 3.64 & 3.90 & 4.19 & 3.23 & 3.75 \\
\hline Openness to change & 4.26 & 4.30 & 4.01 & 4.36 & 5.08 & 4.22 & 4.10 & 4.39 & 4.08 & 4.34 & 4.19 & 4.43 & 4.44 & 4.77 & 4.33 & 4.52 \\
\hline
\end{tabular}

Source: Burgess (2002: 42-44) (Key: A: Asian, B: Black, C: Coloured, W: White)

\section{Methodology}

The objective of this paper was to identify patterns in the portrayal of women in print advertisements. To realise this, the study sought to assess the images of females portrayed as a message source in advertisements in Drum magazine for the cultural characteristics associated with the message sources a case study approach was chosen. Advertisements were collected from randomly chosen years and issues of Drum magazine. Using content analysis techniques, advertisements featuring female message sources were examined by a set of coders were drawn from the magazine's target audience. The coders assessed the advertisements for cultural information using a standard set of cultural statements based on the PVQ.

\subsection{Sample}

The sample universe for this study is all the advertisements that appeared in Drum magazine in the period 1981-2010 that met the following criteria. After pretesting, it was decided to exclude any advertisements in which the women portrayed were smaller than 4.5 centimeters. Advertisements larger than a full page were also excluded because it proved difficult to capture the images for testing. Multistage sampling was used as follows. First, a year was randomly selected. The next step was to select a random sample of months from which advertisements were selected. For each month selected, a census of qualifying advertisements was included in the sample. This sampling procedure resulted in a sample of 244 advertisements. Duplicate advertisements (i.e., defined as advertisements that are similar in all aspects and appear more than once in the same year) were excluded.

\subsection{Content analysis}

The quantitative content analysis approach was used. Coders assessed advertisements for a standardised set of cultural characteristics based on the PVQ (Schwartz, et al. 2001). Coders were asked to examine the advertisements and indicate whether, in their view, each value (as detailed in Table 1) is important or not as a guiding principle in the life of the primary woman in the advertisement on a three-point Likert scale $(0=$ Not important, $1=\mathrm{A}$ little important, and $2=$ Very important). The coders were also provided the opportunity to code "I don't know" where they were not sure about a cultural characteristics presence in an advertisement. However, this response was not used by any of the coders for any of the advertisements. 


\section{Results}

\subsection{Intercoder Reliability}

Intercoder reliability was assessed using Krippendorff's reliability index, a (alpha). Krippendorff's a reliabilities were determined for each of the variables. Though there are many measures of reliability (Lombard, Snyder-Duch \& Bracken 2004), Krippendorff's a is advantageous because it can be used for different scales of measurement, for multiple coders, for data sets that have missing data, and it addresses all the criteria that are required of good measures of reliability (Hayes \& Krippendorff 2007). In content analysis, researchers differentiate between objective content (information on the surface level that can be measured objectively) and subjective content (information that must be inferred subjectively from image content). Unlike objective content, which is more concrete, content analysis of subjective content relies on personal opinion to interpret (Potter \& Levine-Donnerstein 1999). This has implications for levels of agreement between coders. In this paper, the cultural characteristics are measured at the subjective level. Considering that value types and domains are fuzzy rather than discrete factors (Schwartz 1994) and that there may be meaning differences across the population or between people (Burgess 2011), more disagreements were expected amongst the coders. Two adult coders (a female and male) drawn from Drum's target market and who are familiar with the magazine were used to undertake the coding. These coders were trained by the researchers in the type of subjective content of interest.

Though the literature does not provide standards of acceptable reliability, it provides rules of thumb to facilitate assessment of inter-coder reliability. The levels of acceptable reliability reported by Bereleson (1952) range from $66 \%$ to 95\%. Kassarjian (1977) recommends that studies with reliability coefficients of less than $80 \%$ should be treated with caution. Lombard and colleagues argue that coefficients of less than 0.70 are acceptable in exploratory research (Lombard, Synder-Duch \& Bracken 2002). The data collected for all the 244 advertisements was assessed for intercoder reliability on each of the ten PVQ value constructs using Krippendorff's a. This resulted in intercoder reliabilities ranging from 0.95 to 1.00. These levels of reliability are acceptable according to Bereleson (1952), Kassarjian (1977), and Lombard and colleagues (2002).

\subsection{Configural verification}

Since the theorised circumplex structure of value relations is incompatible with structural equation modelling approaches (see Burgess 2011), fit of the data collected in this study to the theorised structure of nomological value relations was assessed by using the configural verification approach (Schwartz, et al. 2001), which employs smallest space analysis (Guttman 1968). Smallest space analysis (SSA) is a nonmetric multidimensional scaling technique. Fit to the theorised structure is assessed using Kruskal's 1964 stress fit index, which measures deviance from a theorised dimensional structure, and by observing the location of the value types in relation to their theorised order on the circular structure (Schwartz 1994). Using Statistica 9 (Statsoft, Inc., 1984-2009), the fit of the Pearson intercorrelations matrix of value relations to a two-dimensional SSA model (stress $=.12$ ) met the criteria of .14, suggested by Schwartz (1992) as an indicator of good fit (see Table 3). As noted earlier, value types in closest proximity on the circular structure are most compatible in their motivational content, while value types with conflicting motivational types are expected to be located in opposition. Small departures from the theorised structure are expected due to differences in meaning across culture. These small departures are more evident when samples of less than 400 cases are used (Schwartz 1992) as in the present research.

Table 3: Multidimensional Scaling Final Configuration (Correlation Matrix)

\begin{tabular}{lcc}
\hline & Final Configuration (Correlation matrix) Stress = .1221734 & \\
\hline & Dimension 1 (DIM. 1) & Dimension 2 (DIM. 2) \\
\hline POW (Power) & -0.484 & -0.170 \\
ACH (Achievement) & -0.664 & -0.767 \\
HED (Hedonism) & 1.922 & 0.034 \\
STM (Stimulation) & 0.699 & -0.014 \\
SDN (Self-direction) & 0.097 & -1.125 \\
UNV (Universalism) & -0.845 & 0.065 \\
BEN (Benevolence) & -0.136 & 0.723 \\
TRD/CNF (Tradition/Conformity) & -0.204 & 0.543 \\
SEC (Security) & -0.385 & 0.711 \\
\hline
\end{tabular}


Inspection of the SSA plot (Figure 2) also suggests a good fit to the theorised structure. For example, the order in which the value types power and achievement appear is the same as predicted by the theoretical model. In the openness to change value domain, the value types hedonism, stimulation, and self-direction are adjacent to each other, but their order of appearance has changed to self-direction, hedonism, and stimulation. The location of self-direction here suggests that it is perceived as a self-enhancement value. This is reasonable given that amongst low income consumers, the pursuit of self-direction may be interpreted as prioritising self-interest and therefore part of the self-enhancement value domain. In the self-transcendence value domain, benevolence emerges jointly with security while universalism takes the place of security. The location of security in the self-transcendence value domain is not in line with the theory and structure of values, but it is not novel in the study of values amongst black South Africans. Schwartz, et al (2001) also found this unusual location of security in the self-transcendence value domain. Except for security which emerged in the selftranscendence region, the value types in the conservation value domain appear as expected according to the theory and structure of values.

The SSA results are impressive considering that people can be expected to report their own values far more accurately than the values of strangers that they observe in advertisements. Also, advertisements often present contrived or fictional situations in which values may be unrealistically portrayed. It is therefore possible that incompatible value types may be crafted into the same advertisement and be perceived by the coders. These points highlight the danger of interpreting these results without regard to the context of the study. Based on the criterion that the maximum possible separation between any pair of values is two places in either direction on the circular structure (Schwartz \& Bilsky 1990), the SSA results indicate a good fit to the theorised structure.

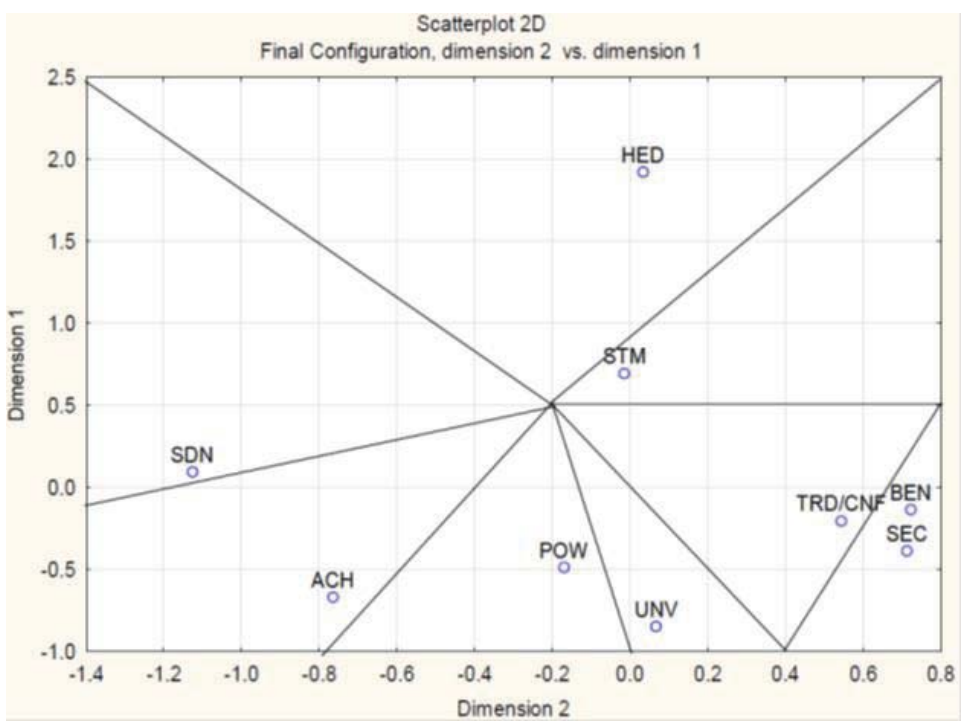

Figure 1: Multidimensional Scaling 2D Scatter Plot (Values Structure)

\subsection{Univariate Statistics}

The advertisements in the sample represented a range of product categories with health and beauty products accounting for $49.6 \%$ of the 244 advertisements analysed, followed by food and financial services at $9.4 \%$ and $9.0 \%$ respectively (Table 4). An analysis of the types of advertisement showed that $92.2 \%$ of the advertisements are for non-housekeeping products, $72.1 \%$ are for gender-neutral products used by both men and women, and that though some advertisements featured home settings (13.5\%) and work settings (6.1\%), most of the advertisements featured staged settings (80.3\%). 
Table 4: Product Categories

\begin{tabular}{lcc}
\hline Category & Number & Percentage \\
\hline Food & 23 & 9.4 \\
Beverages & 8 & 3.3 \\
Health and beauty & 121 & 49.6 \\
Household & 21 & 8.6 \\
Financial services & 22 & 9.0 \\
Travel, transport and leisure & 1 & 0.4 \\
Retail & 10 & 4.1 \\
Government/education & 14 & 5.7 \\
Media promotion & 3 & 1.2 \\
Other & 21 & 8.6 \\
Total & 244 & 100.0 \\
\hline
\end{tabular}

\subsection{Subjective assessment of the cultural characteristics}

The mean ratings and standard deviations regarding the value types are presented in Table 5 . Achievement scored the highest mean rating $(M=1.51, S D=0.785)$ followed by power $(M=1.08, S D=0.847)$ in the self-enhancement value domain $(M=1.29, S D=0.616)$. These findings reveal that the advertisers through message sources in the advertisements placed in Drum magazine emphasise the following value types in order of priority. Firstly, achievement is the most emphasised value type. This is evident when the message sources in the advertisements convey the message that personal success is important and can be realised through demonstrating one's competence in performing the appropriate tasks, and thus achieving some social esteem. Secondly, power is the next most emphasised value type. This is seen when the advertisements also convey the message that social status, prestige, and control over resources including people are important and can engender social esteem.

Table 5: Descriptive Statistics of the Cultural Characteristics of the Message Source

\begin{tabular}{lcc}
\hline Value type & Mean & Standard deviation \\
\hline Power & 1.08 & 0.846 \\
Achievement & 1.51 & 0.785 \\
Hedonism & 0.84 & 0.944 \\
Stimulation & 0.04 & 0.278 \\
Self-Direction & 0.07 & 0.328 \\
Universalism & 0.08 & 0.350 \\
Benevolence & 0.46 & 0.818 \\
Tradition/Conformity & 0.30 & 0.634 \\
Security & 0.14 & 0.475 \\
Value domains & & \\
Openness to change & 0.32 & 0.331 \\
Self-enhancement & 1.29 & 0.616 \\
Conservation & 0.30 & 0.634 \\
Self-transcendence & 0.23 & 0.387 \\
Resultant conservation & -0.02 & 0.760 \\
Resultant self-transcendence & -1.07 & 0.734 \\
\hline
\end{tabular}

\section{Discussion and Conclusion}

The objective of this paper was to identify patterns in the portrayal of women in print advertisements. To realise this, the study sought to assess the images of females portrayed as a message source in advertisements in Drum magazine for the cultural characteristics associated with the message sources. We know from previous studies that the value priorities of South Africans emphasize, in order of importance, security (in the conservation value domain), benevolence (in the self-transcendence domain), and universalism (in the self-transcendence value domain) (Burgess 2002). Another study on value priorities found that the most emphasised values, in order of importance, were security (in the conservation value domain), self-direction (in the openness to change value domain), and benevolence (in the self-transcendence value domain) (Burgess 2011). 
In this study, we found that that the values prioritised in the advertisements were power and achievement (in the self-enhancement value domain. The prioritisation of self-enhancement values in the advertisements means that the messaging was designed to motivate and encourage consumers to "enhance their own personal interests (even at the expense of others)" (Schwartz 1992: 43) by pursuing power and achievement value types. This suggests that the portrayals of message sources focussed on self-interest (the underlying motivational factor in self-enhancement values). However, the findings on self-enhancement values appear to be at variance with the kind of ubuntu-inspired values one would expect to find amongst the readers of Drum. The cultural concept of ubuntu reflects the communal nature of living in African communities. Ubuntu is about the interconnection between the people, their common humanity, and their responsibility to each other (Nussbaum 2003). It encourages supportiveness, communism, cooperation (Koster 1996), compassion, reciprocity, dignity, harmony, and humanity (Nussbaum 2003). Self-interest is expected to be suppressed according to the norms of ubuntu (Mangaliso 2001). As aspects of ubuntu find expression in all spheres of like including social relations, one expects aspects of ubuntu to be evident in advertisements in a magazine like Drum that is targeted at predominantly black African readers. While self-enhancement has self-interest as the underlying motivational factor (Schwartz 1992), ubuntu, similar to self-transcendence values, is about community, sharing, and concern for other. The employment of self-enhancement values in this context suggests that advertisers sometimes employ messages that may be perceived as conflicting in advertisements. This could also prove to be a hindrance to the persuasive effectiveness of the advertisements.

As a source of social influence, advertisements affect consumers through any of three processes, namely compliance, identification, and internalisation (Kelman 1961). The last two are particularly important in the case of this study because they imply that in order to maximise the persuasive effects of advertisements, the advertiser has to employ message sources that enhance the potential for identification and internalisations by the target consumers. In order for identification to take place, consumers must find the message source attractive. For internalisation to take place there must be an alignment between the consumers' value systems and those of the social influence or message source. Messages that fail to foster identification and internalisation are more likely to ineffective and to increase the elaboration demands on the consumer. The use of messages that conflict with consumers' value systems could be a call for more research to understand the consumer behaviour of the target better. This is important because the target consumers and advertising practitioners who in the main belong to what Burgess and Steenkamp (2006) refer as the "urban elite" may not always have shared meanings and values.

This paper has two main limitations. First, the sample of advertisements used was drawn from one magazine only. This limitation offers an opportunity for future research focusing on advertisements from a broader spectrum of magazines covering more diverse audiences. The second limitation is that it focused exclusively on women as message sources. A gender perspective would have required the inclusion of male message sources for comparison purposes and to acknowledge that the way women are portrayed is influenced power relations in society. This limitation also presents an opportunity for future studies to undertake content analyses of advertisements featuring both female and male message sources.

\section{References}

Bandura, A. (1977). Social learning theory. Englewood Cliffs, NJ: Prentice Hall.

Burgess, S. M. (2002). SA Tribes: Who we are, how we live and what we want from life in the new South Africa Claremont: David Philip Publishers.

Burgess, S. M. (2011). Social axioms: A new culture measure for South African business research. South African Journal of Business Management, 42(4), 1-22.

Burgess, S. M., \& Steenkamp, J.-B. E. M. (2006). Marketing Renaissance: Research in Emerging Markets Advances Marketing Science and Practice. International Journal of Research in Marketing 23(4), 337-356.

Charon, J. M. (1995). Symbolic interactionism: An introduction, an interpretation, an integration. Englewood Cliffs: Prentice-Hall.

Clark, J. K., Evans, A. T., \& Wegener, D. T. (2011). Perception of source efficacy and persuasion: Multiple mechanism for source effects on attitudes. European Journal of Social Psychology, 41, n/a. doi: 10.1002/ejsp.787.

Coltrane, S., \& Messineo, M. (2000). The perpetuation of subtle prejudice: Race and gender imagery in 1990s television advertising. Sex Roles, 42(5-6), 363-389.

Connell, R. W. (1987). Gender and power. CA: Stanford University Press.

Cortese, A. J. (1999). Provocateur, images of women and minorities in advertising. Lanham: Rowan \& Littlefield.

Courtney, A. E., \& Lockeretz, S. W. (1971). A woman's place: An analysis of the roles portrayed by women in magazine advertisements. Journal of Marketing Research, 8(1), 92-105.

Davis, D. M. (1990). Portrayal of women in prime-time network television: Some demographic characteristics. Sex Roles, 23(5-6), 325332. 
Gerbner, G., Gross, L., Morgan, M., \& Signorielli, N. (1986). The 'Mainstreaming of America': Violence Profile No. 11. Journal of Communication, 30(3), 10-29.

Goffman, E. (1979). Gender advertisements. Cambridge, MA: Harvard University Press.

Guttman, L. (1968). A general nonmetric technique for finding the smallest coordinate space for a configuration of points. Psychometrika, 33(4), 469-506.

Hayes, A. F., \& Krippendorff, K. (2007). Answering the call for a standard reliability measure for coding data. Communication Methods and Measures, 1(1), 77-89.

Henry, W. A. (1976). Cultural values do correlate with consumer behavior. Journal of Marketing.

Hofstede, G. (1984). Cultural dimensions in management and planning. Asia Pacific Journal of Management, 1(2), 81-99.

Hovland, R., MacMahan, C., Lee, G., Hwang, J.-S., \& Kim, J. (2005). Gender role portrayals in American and Korean advertisements. Sex Roles, 53(11/12), 887-899.

Kassarjian, H. H. (1977). Content analysis in consumer research. Journal of Consumer Research, 4(June), 8-18.

Kelman, H. C. (1961). Processes of Opinion Change. Public Opinion Quarterly, 25(1), 57-78.

Koster, J.D. (1996). Managing the transformation. In K. Bekker (Ed.), Citizen participation in local government, (pp. 99-118). Pretoria: Van Schaik Publishers

Lombard, M., Snyder-Duch, J., \& Bracken, C. C. (2004). A call for standardisation in content analysis reliability. Human Communication Research, 30, 434-437.

Lombard, M., Synder-Duch, J., \& Bracken, C. C. (2002). Content analysis in mass communication: Assessment and reporting of intercoder reliability. Human Communication Research, 24(4), 587-604.

Mangaliso, M. P. (2001). Building competitive advantage from ubuntu: Management lessons from South Africa. Academy of Management Executive, 15(3), 23-33.

McCombs, M. F., Llamas, J. P., Lopez-Escobar, E., \& Rey, F. (1997). Candidate images in Spanish elections: Second-level agendasetting effects. Journalism and Mass Communication Quarterly, 74, 703-717.

McQuail, D. (2000). Mass communication theory (4th ed.). London: Sage.

Milkie, M. A. (1994). Social world approach to cultural studies: Mass media and gender in the adolescent peer group. Journal of Contemporary Ethnography, 23, 354-380.

Morgan, M., \& Signorielli, N. (1990). Cultivation analysis: Conceptualisation and methodology. In N. Signorielli \& M. Morgan (Eds.), Cultivation analysis: New directions in media effects research. New York: Sage.

Moschis, G. P., \& Churchill, G. A. (1978). Consumer socialization: a theoretical and emperical analysis. Journal of Marketing Research, 15(4), 599-609.

Nussbaun, B. (2003). Ubuntu: Reflections of a South African on our common humanity. Reflections, 4(4), 21-26.

O'Kelly, C., \& Bloomquist, L. E. (1976). Women and Blacks on TV. Journal of Communication, 26(4), 179-184.

Potter, W. J., \& Levine-Donnerstein, D. (1999). Rethinking validity and reliability in content analysis. Journal of Applied Communication Research, 27, 258-284.

Rokeach, M. (1973). The nature of human values. New York: Free Press.

Schaeffer, R. T., \& Lamm, R. P. (1992). Sociology (4th ed.). New York: McGraw-Hill.

Schwartz, S. H. (1992). Universals in the content and structure of values: Theoretical advances and empirical tests in 20 countries. In M. P. Zanna (Ed.), Advances in experimental social psychology (Vol. 25, pp. 1-49). Orlando, Florida: Academic Press.

Schwartz, S. H. (1994). Are there universal aspects in the structure and contents of human values? Journal of Social Issues, 50(4), 1945.

Schwartz, S. H., \& Bilsky, W. (1990). Towards a theory of the universal content and structure of values: Extensions and cross cultural replications. Journal of Personality and Social Psychology, 58, 878-891.

Schwartz, S. H., Melech, G., Lehmann, A., Burgess, S. M., Harris, M., \& Owens, V. (2001). Extending the cross-cultural validity of the theory of basic human values with a different method of measurement. Journal of Cross-Cultural Psychology, 32(5), 519-542.

Shrum, L. J. (1996). Psychological processes underlying cultivation effects: further tests of construct accessibility. Human Communications Research, 22(4), 482-509.

Usunier, J.-C., \& Lee, J. A. (2009). Marketing Across Cultures (5th ed.). New York: Prentice Hall. 